\title{
Determinação de Resíduo do Herbicida Fluridone em PeiXe ${ }^{1}$
}

\author{
Determination of Residue of the Herbicide Fluridone in Fish
}

\author{
CAVENAGHI, A.L. ${ }^{2}$, VELINI, E.D. ${ }^{3}$, MARTINS, D. ${ }^{4}$, ANDREOTTI, M. e ATTI, R.J. ${ }^{5}$
}

\begin{abstract}
RESUMO - O objetivo deste trabalho foi desenvolver um método de análise de resíduos do herbicida fluridone em peixes. O herbicida foi extraído do peixe (partes comestiveis), concentrado em colunas de florisil e então analisado em cromatógrafo líquido com detector de UV visível a $313 \mathrm{~nm}$. Os coeficientes de correlação obtidos para linearidade do detector e do método foram de 0,99983 e 0,99987, respectivamente. Com o método descrito foi possível extrair, separar e identificar com eficiência o herbicida fluridone das amostras de peixe, o qual apresentou médias de percentagens de recuperação variando de 60 a $73 \%$. O limite de detecção foi de $20 \mu \mathrm{g} \mathrm{kg}{ }^{-1}$.
\end{abstract}

Palavras-chave: cromatografia, resíduos, peixe, flurione.

ABSTRACT - The aim of this research was to develop an analytical method to detect and quantify residues of fluridone in fish. The herbicide was extracted from edible parts of fish, concentrated in florisil cartridge and then analyzed by HPLC. The detection and quantification were performed by UV absorbance $(313 \mathrm{~nm})$. The correlation values obtained for the linearity of the detector and the method were 0,99983 and 0,99987, respectively. The recovery coefficient ranged from 60 to $73 \%$. The detection limit was $20 \mu \mathrm{g} \mathrm{kg}^{-1}$.

Key words: chromatography, residues, fish, fluridone.

\section{INTRODUÇÃO}

Nos últimos anos, o Brasil tem enfrentado crescentes problemas com plantas aquáticas emersas e imersas presentes em reservatórios destinados a navegação, lazer e turismo e, principalmente, geração de energia. Estas plantas, em corpos d'água eutrofizados, apresentam grande produção de massa, impedindo a navegação, o uso para lazer, além de exigir constante manutenção das grades de tomada d'água de turbinas de hidrelétricas, o que muitas vezes interrompe o processo de geração de energia (Pitelli, 1998; Príncipe et al., 1997; Tanaka, 1998).

O desenvolvimento de métodos de controle de plantas aquáticas, legislações e avaliações dos impactos das aplicações destes métodos faz-se necessário, principalmente pela escassez de informações devido ao recente interesse pelo problema no Brasil.

Para o controle de plantas aquáticas imersas, é utilizado, nos Estados Unidos, o herbicida fluridone (1-methyl-3-phenyl-5-[3(trifluoromethyl) phenyl]-4-(1H)-pyridinone) (Netherland \& Getsinger, 1995a, 1995b; Netherland et al., 1997, 1993; Van \& Steward, 1985). Este herbicida deve permanecer em contato com a planta por um período longo de tempo antes de ser acumulado nos tecidos em niveis suficientes para alcançar um controle propriamente dito (Van \& Steward, 1985), sendo necessárias diversas aplicações em um mesmo local.

Recebido para publicação em 13/11/2001 e na forma revisada em 23/1/2002.

2 Aluno de Pós-Graduação em Doutorado, FCA-UNESP, Caixa Postal 237, 18603-970 Botucatu-SP; ${ }^{3}$ Prof. Assistente Dr., FCA-UNESP. ${ }^{4}$ Prof. Dr. da UNIOESTE, Caixa Postal 91, 85960-000 Marechal Cândido Rondon-PR. ${ }^{5}$ Físico-Químico. Est. Fogolar, 1500, Juquitiba, 06950-000 São Paulo-SP. 
A utilização do herbicida fluridone em reservatórios brasileiros está condicionada ao desenvolvimento de métodos analíticos para estudar sua concentração nos locais onde será aplicado: água, sedimento e organismos vivos, principalmente peixes, que são utilizados para consumo humano. As primeiras análises de fluridone em peixe foram realizadas por West (1978), West et al. (1979) e West et al. (1983), utilizando cromatografia gasosa e detector de captura de elétrons, após metilação da molécula.

O objetivo deste trabalho foi desenvolver um método de análise de resíduos de fluridone em peixe, com intuito de dar suporte às pesquisas com este herbicida nas condições dos reservatórios brasileiros, já que as poucas informações disponíveis referem-se a sistemas hídricos e laboratórios norte-americanos.

\section{MATERIAL E MÉTODOS}

O método foi desenvolvido no laboratório do Núcleo de Pesquisas Avançadas em Matologia, da FCA/UNESP, campus de Botucatu-SP. Os equipamentos e reagentes utilizados foram: (1) padrão analítico de fluridone (Sepro Corporation); (2) erlenmeyer de $250 \mathrm{~mL}$; (3) metanol grau HPLC; (4) acetona grau HPLC; (5) diclorometano grau HPLC; (6) hexano grau HPLC; (7) acetato de etila grau HPLC; (8) solução saturada de cloreto de sódio (370 g de $\mathrm{NaCl} \mathrm{em} 1.000 \mathrm{~mL}$ de água); (9) sulfato de sódio anidro; (10) solução de ácido clorídrico 2 N; (11) água purificada (Máxima Ultra Pure Water ELGA); (12) agitador mecânico orbital; (13) papel - filtro; (14) rotavapor com bomba vácuo; (15) balão para rotavapor de $250 \mathrm{~mL}$; (16) sistema de evaporação termostatizado com atmosfera inerte de nitrogênio; (17) condensador de refluxo refrigerado com água; (18) funil de separação de $250 \mathrm{~mL}$; (19) cartuchos de extração Bakerbond SPE Florisil 1.000 mg; (20) suporte para cartuchos de extração (manifold); (21) seringa de $3 \mathrm{~mL}$ com ponta luer-lock; (22) filtro de seringa de $13 \mathrm{~mm}$ de diâmetro e $0,20 \mu \mathrm{m}$ de porosidade; (23) vials de 8 e $2 \mathrm{~mL}$; (24) cromatógrafo líquido Shimadzu LC-10AD; (25) detector de UV-visivel Shimadzu SPD-10A; (26) coluna cromatográfica Shimadzu CLC-ODS $-\mathrm{C}_{18}$ (4,6 mmID x $150 \mathrm{~mm}$ ); (27) coluna guarda Shimadzu G-ODS (4) (4,6 mmID x 10 mm).
O cromatógrafo utilizado para as análises foi um cromatógrafo líquido com detector de UV visível, operando com fase móvel metanol/ água (60/40\%); fluxo de $1 \mathrm{~mL} / \mathrm{min}$; looping de $100 \mu \mathrm{L}$ para o injetor; comprimento de onda de $313 \mathrm{~nm}$; e sensibilidade de 0,100 AUFS no detector.

Para a implantação do método de análise de fluridone em peixe, foram utilizadas amostras de Curimbatá (Prochilodus sp.) adquirido fresco junto a pescadores no rio Tietê (represa de Barra Bonita). Esta espécie foi escolhida por ser facilmente encontrada nos reservatórios do Estado de São Paulo e fazer parte de programas de repovoamento de peixes em reservatórios do Estado.

No laboratório, as partes comestiveis foram separadas, moídas e colocadas dentro de erlenmeyer de $250 \mathrm{~mL}$ para serem fortificadas com soluções-padrões de fluridone, de forma que as concentrações nas amostras fossem de 100, 200, 400 e $2.000 \mu \mathrm{g} \mathrm{kg}^{-1}$, sendo quatro repetições para cada concentração. Foram utilizados $25 \mathrm{~g}$ de peixe em cada repetição. As concentrações de fluridone utilizadas na fortificação foram escolhidas levando-se em consideração o nível de $500 \mu \mathrm{g} \mathrm{kg}^{-1}$ de fluridone em peixe para consumo humano, estabelecido pela Environmental Protection Agency (EPA), nos Estados Unidos (Lake George Park Commission, 2001).

Na extração do fluridone do peixe, foram adicionados $80 \mathrm{~mL}$ de metanol à amostra, agitados por 14 horas em agitador mecânico. Após a agitação, a solução foi filtrada em papel, transferida para balões de rotavapor e reduzida a um volume próximo a $5 \mathrm{~mL}$, com temperatura máxima de $45{ }^{\circ} \mathrm{C}$.

À solução restante $(5 \mathrm{~mL})$ foram adicionados $30 \mathrm{~mL}$ de ácido clorídrico $2 \mathrm{~N}$, e o balão foi colocado em um condensador de refluxo por uma hora. Após total resfriamento do sistema, $40 \mathrm{~mL}$ de uma solução saturada de cloreto de sódio foram passados pelo condensador e coletado no balão. A solução final foi transferida pra um funil de separação de $250 \mathrm{~mL}$.

O balão vazio foi lavado com $80 \mathrm{~mL}$ de hexano, que foi adicionado à solução no funil de separação, para extração de gordura das amostras. O funil de separação foi agitado por 
um minuto e, após separação das fases (aquosa e hexano), a fase aquosa (fase inferior) foi transferida para um béquer de $150 \mathrm{~mL}$ e o hexano (fase superior) foi descartado. O procedimento foi repetido por mais duas vezes, retornando a fase aquosa para o funil e adicionando-se novas porções de $80 \mathrm{~mL}$ de hexano no funil de separação.

Após a limpeza da solução com hexano, a fase aquosa foi novamente colocada no funil de separação e $60 \mathrm{~mL}$ de acetato de etila foram acrescentados à solução para extração do fluridone da fase aquosa, agitando-se o funil por um minuto. O acetato de etila, após a separação das fases, foi transferido para um balão de rotavapor, passando por um funil com papelfiltro e $12 \mathrm{~g}$ de sulfato de sódio anidro. A solução aquosa foi novamente colocada no funil, repetindo-se o procedimento por mais duas vezes. No final, a solução aquosa foi descartada e o acetato de etila foi totalmente evaporado no rotavapor a uma temperatura máxima de $45 \stackrel{\circ}{\circ}$.

Ao final da secagem, o balão foi lavado com cinco alíquotas de $5 \mathrm{~mL}$ de diclorometano, que foram colocados em um béquer de $50 \mathrm{~mL}$.

A extração do fluridone da solução de diclorometano foi realizada utilizando-se colunas de extração de Florisil (1.000 mg). As colunas foram colocadas em um suporte para extração e condicionadas com $10 \mathrm{~mL}$ de acetona e $10 \mathrm{~mL}$ de diclorometano, passando-se, em seguida, a solução de diclorometano a uma vazão de $5 \mathrm{~mL}$ por minuto. Após a passagem da solução de diclorometano, as colunas foram secas a vácuo total por 30 minutos; em seguida, o fluridone foi extraído das colunas com $5 \mathrm{~mL}$ de acetona e recolhido em vials de $8 \mathrm{~mL}$. A solução de acetona contida nos vials foi totalmente seca em um sistema de evaporação termostatizado com atmosfera inerte de nitrogênio, a uma temperatura máxima de $45^{\circ} \mathrm{C}$. Após a secagem, foram colocados $5 \mathrm{~mL}$ de uma solução de metanol/água (60/40\%) no vial e a solução formada foi filtrada em uma seringa com filtro de $13 \mathrm{~mm}$ de diâmetro e $0,20 \mu \mathrm{m}$ de porosidade e injetada em um cromatógrafo líquido com detector de UV visível.

\section{RESULTADOS E DISCUSSÃO}

A injeção, no cromatógrafo, de padrões de concentração conhecida permitiu obter correlação de 0,99983 (Figura 1) entre as concentrações e áreas dos picos, indicando que a resposta do detector foi praticamente linear entre as concentrações estudadas. De modo análogo, o processamento de amostras contaminadas com concentrações conhecidas de fluridone permitiu obter coeficientes de correlação de 0,99987 (Figura 2) entre tais concentrações e a resposta do detector, indicando elevada linearidade do método como um todo.

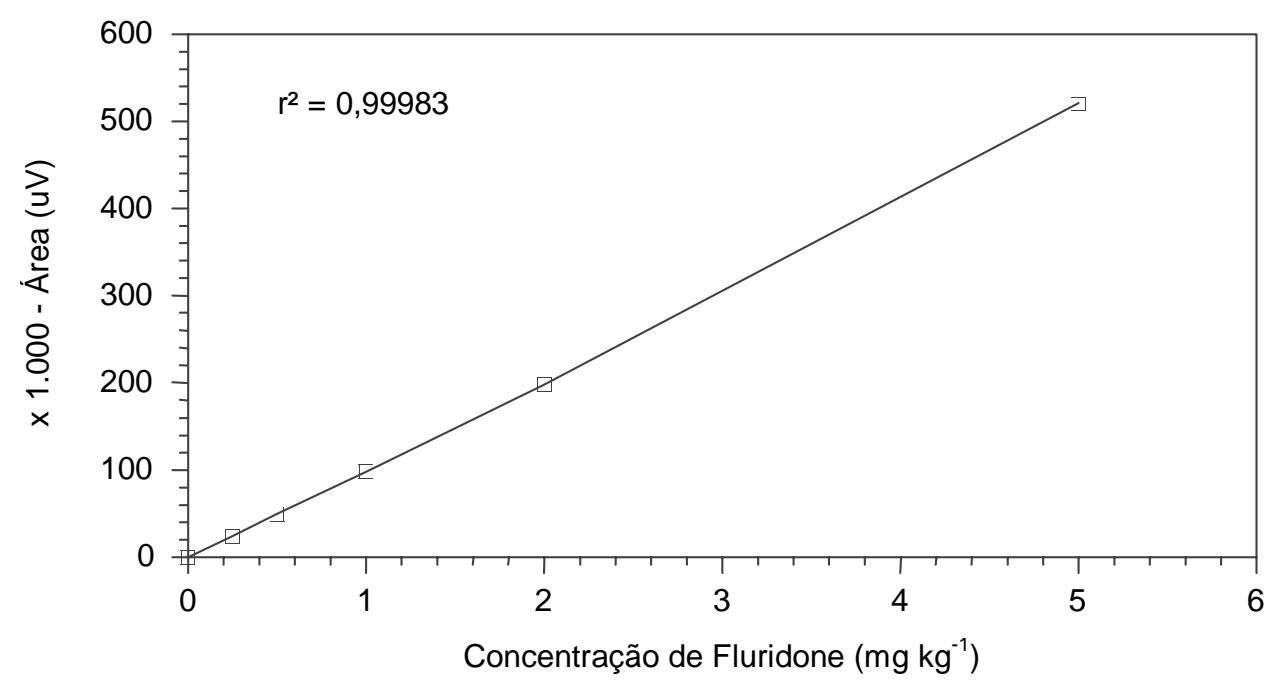

Figura 1 - Linearidade do detector a diferentes concentrações do herbicida fluridone. 


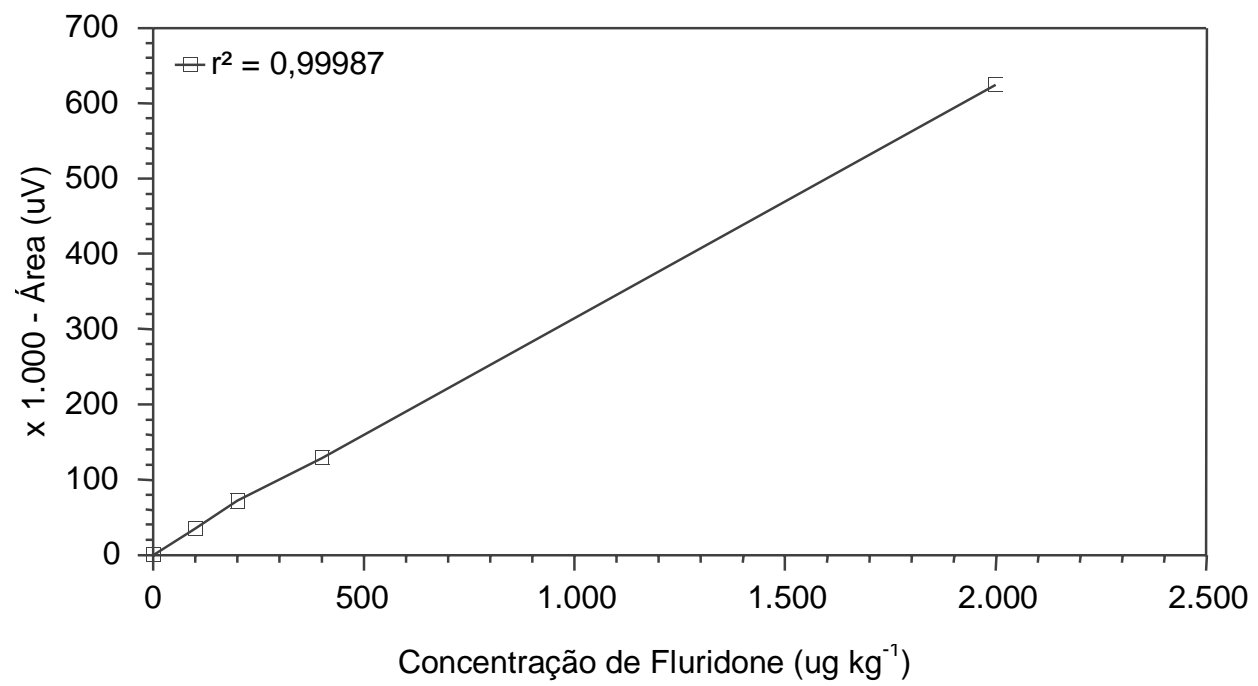

Figura 2 - Linearidade do método a diferentes concentrações do herbicida fluridone.

As percentagens médias de recuperação foram de $71 \%$ para $100 \mu \mathrm{g} \mathrm{kg} \mathrm{kg}^{-1}, 73 \%$ para $200 \mu \mathrm{g} \mathrm{kg}^{-1}$, 65\% para $400 \mu \mathrm{g} \mathrm{kg}^{-1}$ e $60 \%$ para $2.000 \mu \mathrm{g} \mathrm{kg}^{-1}$. West (1978) e West et al. (1979) obtiveram valores médios de recuperação maiores ( 89 e $87 \%$, respectivamente), mas as variações das percentagens de recuperação em função das concentrações foram muito maiores nestes trabalhos (Tabela 1). As percentagens de recuperação obtidas no método desenvolvido são adequadas para matrizes complexas, que requerem diversas etapas de limpeza e purificação do extrato para extração do analito.

Na Figura 3 encontra-se o cromatograma de uma amostra de peixe contaminado com $100 \mu \mathrm{g} \mathrm{kg}^{-1}$ de fluridone, obtido durante o desenvolvimento do método, com tempo de retenção de 7,88 minutos. A coluna cromatográfica Octadesil ODS - $\mathrm{C}_{18}$ utilizada no método mostrou-se eficiente na separação dos compostos presentes na amostra, separando claramente o analito em questão. A variação de 0,1 minuto foi adotada para identificação positiva do herbicida fluridone.

As etapas de limpeza de amostras e a utilização de colunas de florisil e cromatografia líquida com detector de UV visível também mostraram-se eficientes e de fácil execução, descontando-se a não-necessidade de derivatização do herbicida, fundamental para que o herbicida seja analisado por cromatografia gasosa (West, 1978; West et al., 1979).
Tabela 1 - Comparação das variações das percentagens de recuperação entre os trabalhos pesquisados e o método desenvolvido. Valores entre parênteses correspondem às médias das repetições para cada trabalho encontrado

\begin{tabular}{|c|c|c|c|}
\hline \multirow{2}{*}{$\begin{array}{c}\text { Concentrações } \\
(\mathrm{ppb})\end{array}$} & \multicolumn{3}{|c|}{ Variação das porcentagens de recuperação } \\
(média) - \%
\end{tabular}

Mudando-se o volume de fase (metanol/ água) utilizado na diluição da amostra, pouco antes da injeção no cromatógrafo, de $5 \mathrm{~mL}$ para $1 \mathrm{~mL}$, foi possivel aumentar a razão de concentração de fluridone na amostra de 5 para 25 vezes, tornando-se possivel quantificar concentrações abaixo de $20 \mu \mathrm{g} \mathrm{kg} \mathrm{kg}^{-1}$, muito inferior aos $500 \mu \mathrm{g} \mathrm{kg}^{-1}$ tolerados pela legislação norte-americana vigente.

Com o procedimento descrito foi possível extrair, separar e identificar com eficiência o herbicida fluridone de amostras de peixe utilizadas no desenvolvimento do método analítico, o que possibilita desenvolver estudos com este herbicida tanto na área de controle de plantas aquáticas como ambiental. 


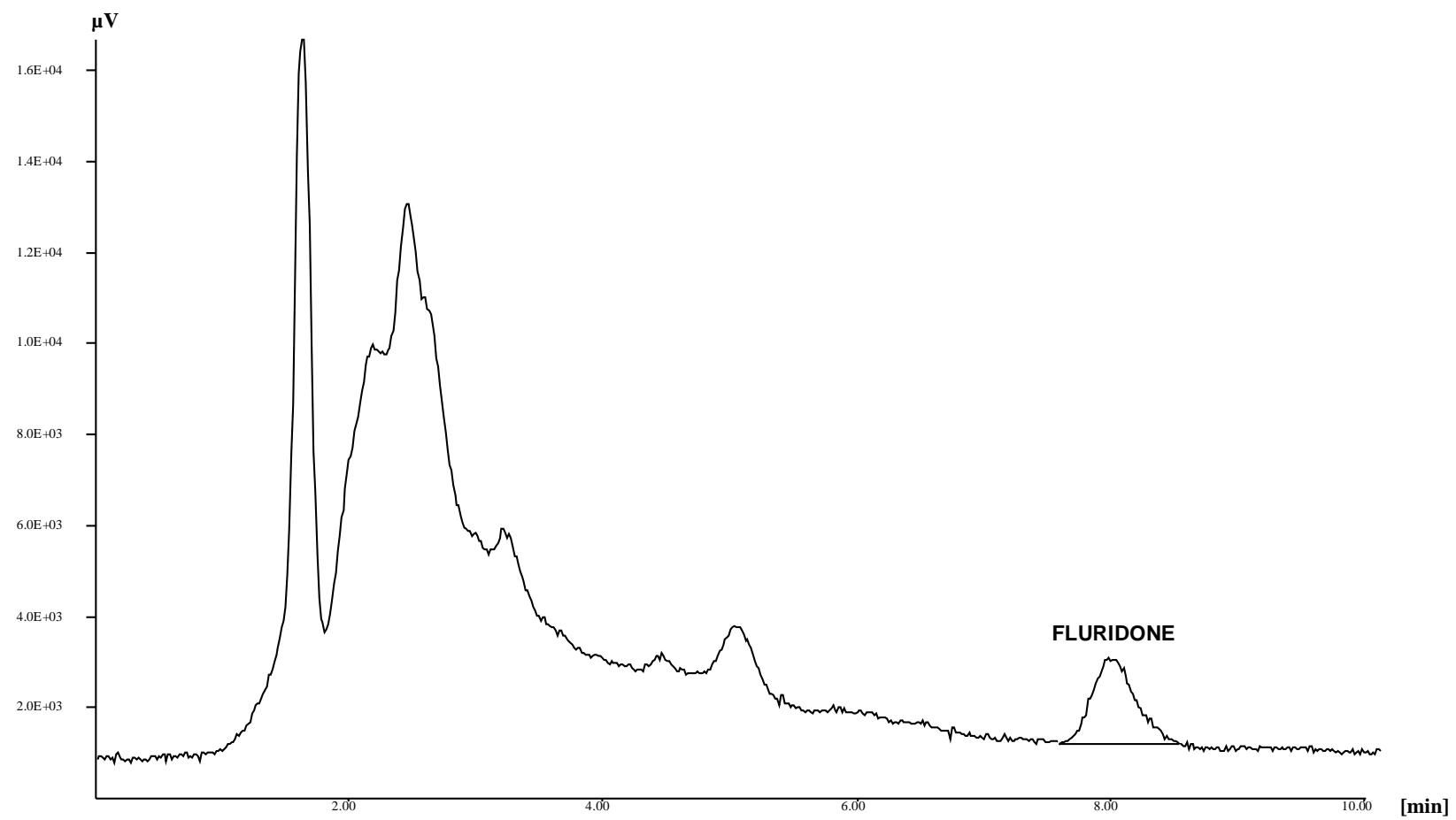

Figura 3 - Cromatograma de uma amostra de peixe contaminada com 100 ppb de fluridone.

\section{LITERATURA CITADA}

LAKE GEORGE PARK COMMISSION - LGPC. Supplemental environmental impact statement for the control of eurasian watermilfoil in Lake George with fluridone: final SEIS (June 2001). New York: ENSR, 2001. Disponível: http://www.lgpc.state.ny.us/fseisson.pdf. Acesso em: 28 de Dez 2001.

NETHERLAND, M. D.; GETSINGER, K. D. Laboratory evaluation of threshold fluridone concentration under static conditions fro controlling Hydrilla and Eurasian watermilfoil. J. Aquatic. Plant. Manag., v. 33, p. 33-36, 1995a.

NETHERLAND, M. D.; GETSINGER, K. D. Potential control of Hydrilla and Eurasian watermilfoil under various fluridone half-life scenarios. J. Aquatic. Plant Manag., v. 33, p. 36-42, 1995 b.

NETHERLAND, M. D.; GETSINGER, K. D.; SKOGERBOE, J. D. Mesocosm evaluation of the speciesselective potential of fluridone. J. Aquatic. Plant Manag., v. 35, p. 41-50, 1997.

NETHERLAND, M. D.; GETSINGER, K. D.; TURNER, E.G. Fluridone concentration and exposure time requirements for control of Eurasian watermilfoil and Hydrilla. J. Aquatic. Plant Manag., v. 31, p. 189-194, 1993.
PITELLI, R. Macrófitas aquáticas no Brasil, na condição de problemáticas. Controle de plantas aquáticas. Brasília: IBAMA, 1998. p. 12-15.

PRÍNCIPE, C. R.; KURATANI, H.; MELONI, M. L. B. Impactos da afluência de Elódea na operação e manutenção da Usina Hidrelétrica Eng. Souza Dias (Jupiá) - CESP. In: Plantas aquáticas. In: CONGRESSO BRASILEIRO DA CIÊNCIA DAS PLANTAS DANINHAS, 21, 1997, Caxambu. Anais... Caxambu: 1997. p. 5-8.

TANAKA, R. Prejuízos provocados pelas plantas. Controle de plantas aquáticas. Brasília: IBAMA, 1998. p. 36-38.

VAN, T. K.; STEWARD, K K. The use of controlled-release fluridone fibers for control of hydrilla (Hydrilla verticillata). Weed Sci., v. 34, p. 70-76, 1985.

WEST, S. D. Determination of residue levels of the herbicide fluridone by eletron-capture gas chromatography. J. Agric. Food Chem., v. 26, n. 3, p.644-646, 1978.

WEST, S. D. et al. Bioconcentration and field dissipation of the aquatic herbicide fluridone and its degradation products in aquatic environments. J. Agric. Food Chem., v. 31, p. $579-585,1983$.

WEST, S. D.; DAY Jr., E. W.; BURGER, R. O. Dissipation of the experimental aquatic herbicide fluridone from lakes and ponds. J. Agric. Food Chem., v. 27, n. 5, p. 1067-1072, 1979. 